\title{
PENGENALAN MOTIF KARAWO MENGGUNAKAN EKSTRAKSI FITUR SIFT DAN APPROXIMATE NEAREST NEIGHBOR
}

\author{
Syahrial, Supriadi Rustad, Purwanto, Moch. Arief Soeleman \\ Pasca Sarjana Teknik Informatika Universitas Dian Nuswantoro
}

\begin{abstract}
An art culture from Gorontalo became iconic handcraft is kerawang or karawo. The word "karawo" came from root word of "mokarawo" which means slicing or making holes. It's created with precision, carefulness, and patience in work using handmade masterpiece. Pattern of karawo itself held four kinds which is flora, fauna, geometric, and nature. From those kinds born vary pattern which come difficult to identify both its names and its kind. Karawo patterns can be form as a single pattern or a pattern that it parts came from several or many pattern combined. Those patterns had its own characteristic from shape and scale perspective. Identifying single pattern on combined pattern are particularly a problem because it's combined inpvolve scaling and rotation. This research is recognizing single pattern on combined pattern using feature extraction SIFT algorithm which is capable extract feature that invariant from scale and rotation. Feature matching using approximate nearest neighbor (aNN) for similarity of features labor best bin first strategy on kd-tree data structure. Those methods can be a reference to recognize single pattern on combined pattern using from range 5 to 20 match features as a threshold. Testing result indicated recognition accuracy is good which range form $76.36 \%$ to $85.45 \%$ on recognize the kind of karawo pattern and $76.36 \%$ on its name.
\end{abstract}

Keywords: karawo, pattern recognition, feature extraction, sift, approximate nearest neighbor, $k d$-tree, best bin first.

\section{PENDAHULUAN}

\section{a) Latar Belakang}

Karawo merupakan salah satu kerajinan tangan sulaman kain khas Gorontalo yang menerapkan proses pengirisan atau pelubangan. Kerajinan tangan ini dikerjakan dengan penuh ketelitian, kejelian, ketelatenan, kepekaan dan kesabaran dalam membentuk suatu motif dalam kain [1]. Motif atau ragam hias Karawo itu sendiri terdapat empat jenis motif yaitu: motif flora, motif fauna, motif geometris, dan motif alam [2]. Jenis-jenis tersebut melahirkan banyak motif baik berupa motif tunggal atau motif kombinasi. Motif tunggal merupakan motif yang merepresentasikan suatu bentuk benda nyata atau simbol budaya yang sederhana dan dapat berdiri sendiri sebagai sebuah motif. Motif kombinasi adalah motif yang terbentuk dari beberapa motif tunggal yang dipadukan. Perpaduan tersebut sering menerapkan perubahan dalam bentuk rotasi, distorsi, dilasi atau penskalaan, dan deformasi.

Indentifikasi motif-motif tunggal yang dipadukan sehingga membentuk motif baru menjadi masalah tersendiri karena menyangkut keaslian dari motif tersebut. Para desainer motif karawo sering mengklaim motif yang mereka buat merupakan karya aslinya akan tetapi dalam motif tersebut sering memadukan motif-motif tunggal yang sudah pernah ada. Motif-motif ini tentunya mempunyai karakteristik tersendiri ditinjau dari bentuk dan ukuran serta asalnya. Hal ini juga menyangkut hak cipta dari motif tersebut yang mestinya tidak dilanggar oleh setiap desainer motif.

Penelitian sebelumnya mengenai kerajinan Karawo telah dilakukan oleh Rahmatiah tentang industrialisasi kerajinan Karawo [1] mengemukakan bahwa peran modal manusia dalam industri karawo harus mendapatkan pengetahun lebih banyak. Hasdiana meneliti tentang peningkatan Brand 
Image kerajinan kerawang Gorontalo atau karawo [2] menyatakan bahwa motif kerawang pada karawo adalah motif spesifik dan merupakan ciri khusus dari ekstraksi budaya Gorontalo, selanjutnya A. Mulyanto meneliti tentang klasifikasi karakter pengguna Karawo menggunakan Naive Bayes [3] melakukan identifikasi dan desain motif karawo serta klasifikasi karakter pengguna dengan akurasi $90,48 \%$, serta M. Koniyo meneliti tentang pengembangan aplikasi yang dapat memberikan rekomendasi motif karawo disesuaikan dengan karakter dari pengguna [4].

Penelitian pengenalan motif sebelumnya dilakukan pada motif batik. Beberapa algoritma yang dapat diterapkan dalam pengenalan motif batik dikemukakan oleh B. Arisandi menggunakan Rotated Wavelet Filter dan Neural Network dengan akurasi $100 \%$ pada data testing sama dengan data training serta akurasi 78,26\% pada data training berbeda [5]. Berikutnya M. Suryawan menulis, identifikasi motif batik dengan algoritma C4.5 berdasarkan orientasi objek [6]. Selanjutnya J. Yodha menulis, pengenalan menggunakan algoritma Deteksi Tepi Canny dan $k$ - $N N$ dengan akurasi 66,67\% dan k=1 [7]. Kemudian I. Nurhaida menulis, penggunaan algoritma scale invariant feature transform (SIFT) (SIFT untuk ekstraksi fitur dan Voting Hough Transform untuk pengenalan) menghasilkan equal error rate (EER) sebesar 8,47\% dibandingkan SIFT asli EER sebesar 26,60\% [8]. Hal ini menunjukkan bahwa algoritma SIFT dapat digunakan untuk ekstraksi fitur dalam pengenalan dengan akurasi tinggi pada pengenalan motif batik dibandingkan dengan algoritma yang lain tersebut sebelumnya.

Penggunaan algoritma SIFT dan variannya digunakan secara umum pada penelitian ekstraksi fitur dengan dataset yang berbeda-beda. SIFT pertama kali dikemukakan oleh D. Lowe yang menulis, ekstraksi fitur dari gambar menggunakan SIFT dapat mengidentifikasi objek pada gambar yang tidak terpengaruh pada skala dan rotasi serta handal pada pergeseran pandangan 3D [9]. Pengenalan wajah menggunakan fitur SIFT menunjukkan hasil yang baik [10], pengenalan aksi pada citra [11], dan dipertegas dalam [12] serta [13]. Berikutnya oleh Yan Ke and R. Sukthankar menulis, kombinasi algoritma principal component analysis (PCA) dan SIFT lebih handal pada gambar yang berubah bentuk atau deformation [14]. Selanjutnya SIFT dalam pengenalan dengan pendekatan probabilistik memberikan hasil yang baik untuk membandingkan pasangan gambar stereo serta untuk perhitungan korespondensi dalam rekostruksi 3D [15].

Proses pengenalan motif dengan menggunakan ekstraksi fitur SIFT yaitu membandingkan fitur (dalam hal ini keypoint dan descriptor) dari training ke fitur dari target atau data testing. Pembandingan fitur tersebut umumnya menggunakan kedekatan jarak atau Euclidean distance antara keypoint training dan testing. Kesamaan keypoint ditentukan oleh jarak terdekat pertama kurang dari perkalian jarak terdekat kedua dengan rasio yang telah ditentukan [9]. Feature matching lainnya seperti: Approximate Nearest Neighbor (aNN) [16] yang menggunakan struktur data KD-tree dan strategi Best Bin First [16], [17], Random Sample Consensus (RANSAC) [18], dan Voting Hough Transform [8].

\section{b) Rumusan Masalah}

Motif tunggal sering dipadukan dengan motif lainnya untuk membentuk motif baru oleh pada desainer motif sehingga menjadi pertanyaan menyangkut keaslian dari motif tersebut. Motif tunggal tersebut dimasukkan dalam motif kombinasi dengan melakukan pengubahan skala dan atau dilakukan rotasi sehingga menyulitkan dalam proses pengenalan nama motif tunggal serta jenisnya.

\section{c) Tujuan}

Penelitian ini bertujuan untuk mengenali motif karawo tunggal pada motif kombinasi sehingga dapat dijadikan pengontrol desainer dalam mendesain motif mengedepankan kreatifitas tanpa mengambil motif tunggal yang umum. 


\section{d) Manfaat}

Manfaat penelitian ini secara praktisnya untuk mengontrol desainer motif karawo dalam mendesain motif baru yang mengedepankan kreatifitas sendiri dan tidak mengambil atau meniru motif tunggal umum sehingga kreatifitas desainer dapat ditingkatkan. Manfaatnya secara teoritis dapat menghasilkan potensi di bidang industri Karawo khususnya pada motif Karawo dan ilmu pengetahuan sehingga kualitas dapat ditingkatkan dengan signifikan. Penelitian ini dapat menjadi referensi untuk peneliti berikutnya dalam pengembangan bidang pengolahan citra khususnya pengenalan motif karawo Gorontalo serta memberikan tambahan pengetahuan dalam penerapan ilmu komputer pada lingkungan pendidikan khususnya di bidang pengolahan citra.

\section{TINJAUAN PUSTAKA}

\subsection{Penelitian Terkait}

Dalam penelitian pengenalan atau identifikasi objek motif khusus pada citra motif Karawo belum pernah dilakukan sepanjang penulis ketahui saat ini. Penelitian tentang pengenalan dengan dataset citra motif lainnya seperti batik sudah pernah dilakukan oleh B. Arisandi, N. Suciati, dan A. Wijaya [5] melakukan pengenalan motif batik. Metode yang digunakan adalah Rotated Wavelet Filter dan Neural Network. Dataset yang digunakan berupa 228 citra batik, yang terbagi menjadi dataset training sebanyak 182 citra dan dataset testing sebanyak 46 citra. Ekstraksi fitur tekstur dilakukan baik pada data training maupun pada data testing dengan Rotated Wavelet Transform dan Discrete Wavelet Transform yang kemudian dihitung Energy dan Standar Deviation. Keseluruhan uji coba diperoleh akurasi tertinggi $100 \%$ untuk data testing data sama dengan data training dan 78,26\% untuk data testing berbeda dengan data training. Akurasi tertinggi tersebut didapat pada nilai learning rate 0,8 ; momentum 0,9; komposisi node hidden layer [20 10 1], dan level dekomposisi ke-5.

Penelitian yang dilakukan oleh A. Rangkuti, A. Harjoko, dan A. Putro [19] tentang temu kembali citra batik. Dataset menggunakan citra motif batik yang dibagi 3 berdasarkan ukuran: kecil menengah, besar.Jumlah citra motif sebanyak 300 untuk training dan 22 motif untuk testing. Metode yang digunakan terbagi 2 yaitu: ekstraksi fitur bentuk menggunakan Invariant Moment dan fitur tekstur menggunakan Edge Detection dan Wavelet Transform Daubechies Type 2. Wavelet Transform dihitung berdasarkan nilai dari mean, energy, entropy dan standard deviation dari citra. Percobaan menunjukkan hasil metode Daubechies type 2 tingkat kesamaan rata-rata motif tinggi dibandingkan dengan metode lainnya. Tingkat kesamaan yang rendah oleh semua metode pada motif megamendung. Secara umum pada semua motif selain megamendung tingkat akurasinya diatas $80 \%$.

Penelitian klasifikasi citra batik oleh A. Kurniawardhani, Nanik Suciati, dan I. Arieshanti [20] mengenai klasifikasi yang invariant terhadap rotasi dengan pembandingan beberapa metode. Dataset citra motif diambil dari koleksi dalam buku dan dari internet. Citra motif tersebut dibagi dalam 9 kelas motif dasar, seperti: Banji, Ceplok, Kawung, Tambal, Parang, Udan Liris, Semen, dan Buketan. Penelitian ini juga menggunakan dataset Brodatz yang merupakan dataset publik untuk ekstraksi fitur tekstur. Metode yang digunakan berupa Local Binary Patter Rotation (LBPROT), Compound Local Binary Pattern dengan rotasi dan magnitude (rotCLBP_M), dan Completed Robust Local Binary Pattern dengan rotasi dan magnitude (rotCRLBP_M). klasifikasi yang digunakan adalah Probabilistic Neural Network (PNN). Hasil pembandingan berdasarkan rotasi pada dataset batik dengan akurasi tinggi pada rotCRLBP_M sebesar 90,34\%. Pada dataset brodatz akurasi tertinggi juga didapatkan pada rotCRLBP_M sebesar $87,92 \%$. Perbandingan terhadap skala menunjukkan rotCRLBP_M dan rotCLBP_M sama-sama menghasilkan akurasi tertinggi sebesar 73,33\% pada dataset batik. Pada dataset brodatz metode rotCRLBP_M menghasilkan akurasi tertinggi sebesar $67,78 \%$.

Penelitian pengenalan batik juga dilakukan oleh J. Yodha dan A. Kurniawan [7] memanfaatkan algoritma deteksi tepi Canny dan klasifikasi k-Nearest Neighbor $(\mathrm{kNN})$. Dataset yang dipakai berjumlah 300 dalam penelitian ini. Dataset ini dibagi ke dalam 3 kelompok data training: 210, 240, 
270 dengan jumlah kelas sebanyak 6. Dataset testing berjumlah 30 dan pada masing-masing berjumlah kelas sama. Metode ekstraksi fitur deteksi tepi Canny diterapkan pemisahan motif dari latarnya setelah melalui perubahan citra warna ke citra Grayscale dan Histogram Equalization serta pengubahan ukuran ke 128x128. Hasil pengujian yang dilakukan memakai data testing yang sama dengan data training, tingkat pengenalan pola motif tertinggi ditunjukkan pada saat data testing dan data training diklasifikasikan menggunakan $\mathrm{k}$ (jumlah ketetanggaan) $=1$ dengan hasil akurasi sebesar 100\%. Pada pengujian menggunakan 210 data training menghasilkan akurasi sebesar 56,67\%. Data training kemudian ditingkatkan dengan menggunakan 240 citra, menghasilkan akurasi sebesar $66,67 \%$. Terakhir menggunakan 270 data training dan menghasilkan akurasi sebesar 66,67\%.

Penelitian yang dilakukan oleh K. Nugraha, W. Hapsari, N. Haryono [21] meneliti tentang komponen apa yang dominan dalam fitur tekstur dari batik. Dataset yang digunakan diambil dari beberapa buku yang berisi motif batik dan dibuat kumpulan motif batik beserta nama dari tiap kelasnya. Jumlah dataset training sebanyak 20 untuk setiap jenis motif, dengan jumlah keseluruhan sebanyak 80 buah motif batik. Sedangkan jumlah data testing sebanyak 10 data untuk setiap jenis motif, sehingga jumlahnya sebanyak 40 buah data. Proses klasifikasi Batik dibangun menggunakan Matlab serta hampir semua fungsi yang dipakai sudah tersedia didalamnya. Klasifikasi diterapkan menggunakan perhitungan selisih jarak dari nilai ekstraksi yang telah diterapkan normalisasi, sehingga nilai jarak berada antara 0 dan 1 antara ekstraksi fitur. Selanjutnya jarak disatukan untuk membentuk komponen utama dari semua komponen ekstraksi fitur. Komponen ini selanjutnya akan diuji dengan pemberian nilai bobot sebesar $70 \%$. Pada tiga komponen lainnya diberikan masing-masing bobot 10\%.[21]. Pengujian klasifikasi menggunakan k-NN menunjukkan akurasi sebesar $60 \%$ pada $\mathrm{k}=5$.

Pada penelitian I Setyawan, I. Timotius, M.Kalvin [22], meneliti tentang klasifikasi batik dengan ekstraksi fitur SIFT dengan k-NN. Dataset berupa motif batik dari koleksi Museum Batik Danar Hadi, Solo. Pengambilan dengan kamera setting auto tanpa flash hanya menggunakan pencahayaan dari ruangan. Dataset berjumlah pada 70 citra training yang kemudian dikelompokkan dalam 7 kelas. Sedangkan jumlah citra testing sebanyak 30. Semua ukuran baik citra training maupun citra testing menggunakan ukuran 500x331. Metode ekstraksi yang digunakan adalah berbagai moment fitur SIFT tanpa menggunakan semua descriptor dari SIFT. Dataset training melalui perhitungan moment berupa mean $\mu X$, variance $\sigma^{2} X$, standard deviation $\sigma X$, skewness $\sigma_{3} X$ dan kurtosis $\sigma_{4} X$. Hasil memperlihatkan bahwa rata-rata akurasi $31,43 \%$ untuk 7 kelas motif tanpa ada kelas motif yang tanpa kelas.

Penelitian lain yang dilakukan oleh I. Nurhaida, A. Noviyanto, R. Manurung, dan A. Arymurthy pada batik berdasarkan variasi posisi dari pola dasar [8]. Dataset yang digunakan berjumlah 120 yang berasal dari 20 pola batik dasar yang dibuat masing-masing 6 variasi posisi. Penelitian ini menggunakan metode ekstraksi fitur SIFT dan selanjutnya dilakukan voting keypoint posisi dengan Hough Transform minimal 3 yang sama pada bins diidentifikasi pola yang sama. Prosedur pencocokan menggunakan threshold 1.0 dan menggunakan hough transform untuk melihat pasangan keypoint yang konsisten pada posisi yang sama. Voting dilakukan untuk mengeliminasi yang tidak konsisten pada korespondensi geometrisnya. Hasil penelitian ini menunjukkan bahwa SIFT dan voting Hough Transform menghasilkan EER 8,47\% pada threshold 30 dibandingkan dengan hasil SIFT asli EER 26,60\% pada threshold 19.

Pencocokan fitur SIFT dapat dilakukan hanya dengan membandingkan semua descriptor antara dua fitur yang masing-masing berjumlah 128 berdasarkan perhitungan jarak. Namun, pencocokan tersebut belum menunjukkan tingkat kesamaan dalam hal tetangga terdekatnya. Solusi yang diberikan oleh penelitian sebelumnya dengan memanfaatkan pencarian tetangga terdekat yang mendekati (approximate nearest neighbor-aNN). Penelitian yang dilakukan oleh S.Arya, D.Mount, N.Netanyahu, dan A.Wu [23] mengemukakan pencarian aNN pada dimensi tetap. Dataset yang digunakan adalah 100.000 data titik dalam dimensi 16 dan dihitung berdasarkan 1000 titik query. Model pencarian aNN dalam bentuk KD-tree yang didistribusikan merata. Hasil menunjukan pencarian aNN dengan KD-tree lebih baik dalam hal waktu pencarian. 
Penggunaan Approximate Nearest Neighbor (aNN) dalam pencarian tetangga terdekat juga dikemukakan oleh Beis dan Lowe [16] untuk pencarian tetangga terdekat dalam KD-tree dengan pendekatan best bin first (BBF). Penelitian ini mengangkat masalah shape indexing pada database besar dan menggunakan fitur high-dimensional. Dataset berupa titik acak pada unit hypercube yang didistribusikan merata untuk membentuk masalah 1-NN. Parameter yang digunakan adalah $D=$ $12, N=10^{5}, E_{\max }=200$ yang diterapkan pada struktur data KD-tree. Solusi yang diberikan berupa model pencarian yang tidak mencari secara keseluruhan dalam node tetapi hanya mencari pada node yang terbaik saja. Hasil pencarian menunjukkan BBF dapat mencari $94 \%$ tetangga terdekat dibandingkan dengan pencarian terbatas (restricted search) yang menghasilkan 59\%.

Penerapan KD-tree dalam pencocokan fitur dari sidik jari dikemukakan oleh P.Browmick dan B. Bhattacharya [24]. Permasalahan yang diangkat adalah pengenalan sidik jari berdasarkan minutiae. Solusi yang diberikan dengan membentuk struktur data KD-tree dan representasi minutiae. Dataset yang digunakan NIST Special Database (size 80x512,500 dpi) terdiri dari 100 citra dari 50 sidik jari atau 2 citra untuk tiap sidik jari. Dataset lain adalah database dB1a dari FVC2000 (size: 300x300, 500 dpi) terdiri 800 citra dari 100 sidik jari atau 8 citra untuk setiap sidik jarinya. Hasil menunjukkan pembandingan Authentic Acceptance Rate (AAR) dengan False Acceptance Rate (FAR) untuk menunjukkan Receiver Operating Characteristic (ROC) pada kedua database dengan hasil yang baik.

Penelitian selanjutnya dilakukan BBF oleh J.Kybic dan I.Vnucko [17] mengangkat masalah pencarian tetangga terdekat (nearest neighbor-NN) pada titik-titik berdimensi sedang sampai tinggi. Solusi yang diberikan dengan pencarian dilakukan pada optimasi struktur data KD-tree dengan penggunaan strategi BBF dan balanced box-decomposition (BBD). Node terdiri dari tight bounding box (TBB) dan loose bounding box (LBB). Perhitungan jarak kedekatan menggunakan $\iota_{\infty}$ norm. Hasil menunjukkan waktu pencarian secara signifikan menurun.

Berdasarkan dari penelitian-penelitian diatas, pada penelitian ini penulis menggunakan dataset motif Karawo serta menggunakan fitur ekstraksi SIFT dan pencocokan fitur Approximate Nearest Neighbor (aNN). Penggunaan fitur SIFT didasari pada penelitian-penelitian terdahulu [8], [11], [12], [15], [25] yang menyatakan fitur SIFT handal dalam perubahan skala, rotasi, dan pencahayaan sehingga diharapkan dapat mengekstrak fitur motif Karawo dengan baik. Pencocokan fitur training dengan fitur testing akan menggunakan aNN sesuai yang dikemukakan oleh D. Lowe [9] penggunaan struktur data KD-tree dan strategi best bin first [17]. Pencocokan fitur tersebut diharapkan dapat mengidentifikasi motif tunggal dalam motif kombinasi.

\subsection{Landasan Teori}

\section{a) Scale Invariant Feature Transform (SIFT)}

SIFT merupakan algoritma untuk mendeteksi dan mendeskripsikan fitur-fitur lokal dari suatu citra. SIFT dikembangkan oleh D. Lowe [9], [26], terkenal untuk mencari keypoint dan fitur descriptor yang tidak terpengaruh pada skala, rotasi, pencahayaan, pergeseran, persepektif, dan noise. Langkahlangkah metode SIFT sebagai berikut:

1) Scale-space extrema detection: tahapan yang dilakukan untuk mencari nilai ektremum ( maksimum dan minimum) dengan pembentukan Gaussian Scale Space dan Difference of Gaussian Scale Space.

2) Keypoint localization: pada setiap calon keypoint, model detail dicocokkan dengan data sekitarnya untuk lokasi, rasio, dan skala yang selanjutnya diseleksi berdasarkan ukuran kestabilannya. Proses eliminasi terhadap titik yang merupakan titik yang memiliki kontras rendah atau berada pada sisi atau tepi dari garis.

3) Orientation assignment: penetapan satu atau beberapa orientasi pada keypoint berdasarkan arah dari gradient. Penetapan pada orientasi yang konsisten pada setiap keypoint berdasarkan properties lokal dari gambar. 
4) Keypoint descriptor: menghitung gradient citra pada skala yang ditentukan berdasarkan area sekeliling keypoint. Penciri dibuat dengan menghitung histogram orientasinya pada citra dalam area sekeliling lokasi keypoint.

\section{b) Approximate Nearest Neighbor (aNN)}

Nearest Neighbor Search adalah bagian fundamental dari banyak algoritma pada bidang computer vision dan secara signifikan penting di berbagai bidang lainnya. Secara umum teknik nearest neighbor terbagi dalam 3 kategori yaitu: partitioning trees, teknik hashing dan teknik neighboring graph [27]. aNN dipertimbangkan untuk mengatasi masalah pencarian ruang high-dimensional dan pada banyak titik karena kadang exact nearest neighbor (eNN) memerlukan waktu komputasi yang lebih dari banyak penerapannya. Metode ini akan mendapatkan tetangga terdekat sebenarnya tapi juga mencari titik $S$ yang mendekati dari tetangga terdekat tersebut. Kedekatan ditentukan dengan jarak kedekatan $(1+\epsilon) \varrho_{q}$ yang mana $\varrho_{q}$ merupakan tetangga terdekat sebenarnya.

\section{c) K-Dimensional-Tree (KD-tree)}

KD-tree atau K Dimensional tree merupakan salah satu algoritma Nearest Neighbor Search yang menggunakan teknik partitioning tree dan merupakan binary space partitioning tree. KD-Tree (KDimensional Tree) merupakan representasi data multidimensional dalam bentuk binary tree yang bertujuan untuk memisahkan setiap data dalam suatu area tertentu berdasarkan nilai posisinya [28]. Struktur data ini umumnya diaplikasikan pada pencarian banyak kunci atau multidimensional key seperti: pencarian pada rentang (range search) dan pencarian ketetanggaan terdekat (nearest neighbor search). Langkah-langkah pembentukan tree pada KD-tree sebagai berikut [29]:

Prosedur kd_tree (daftar_titik, kedalaman)

1. Pilih atribut atau axis yang sebagai pembatas (axis = kedalaman modulus $\mathrm{k}$ ) atau axis dapat berupa yang terpanjang dimensinya.

2. Urutkan data sesuai axis yang tentukan kemudian cari median atau mean sebagai nilai pemisahnya.

3. Buat node dan beserta cabangnya memanfaatkan fungsi rekursif:

node.cabangKiri := kd_tree(titik sebelah kiri nilai pemisah, kedalaman+1);

node.cabangKanan := kd_tree(titik sebelah kanan nilai pemisah, kedalaman+1);

\section{d) Best Bin First (BBF)}

Strategi dalam pencarian beberapa nilai nearest neighbor pada nilai target salah satunya adalah best bin first. Penerapan BBF digunakan dalam pencarian approximate NN dalam struktur data KD-tree. Untuk mengatasi masalah waktu komputasi dari KD-tree menurun drastis saat dimensinya mulai banyak dalam pencariannya. Pada dasarnya BBF menampung semua jarak dan posisi dalam keranjang dari semua internal node terhadap target dan melanjutkan pencarian pada node yang memiliki jarak minimal. Performa dari pencarian BBF ditunjukkan oleh Beis dan Lowe [16]. Langkah-langkah dalam BBF dalam pencarian approximate NN sebagai berikut:

1. Pencarian di mulai dalam root node dengan menghitung nilai jarak dari semua internal node dan disimpan dalam keranjang (bin) berupa posisi dan jaraknya.

2. Cari jarak paling minimal dalam keranjang dan jadikan rujukan pencarian dalam node tersebut.

3. Masuk kedalam node yang memiliki nilai minimal dan menghitung nilai jarak semua internal node didalamnya dan dimasukkan dalam keranjang untuk dihitung jarak paling minimal seperti langkah 2, dan seterusnya. 


\section{e) Evaluasi Confusion Matrix}

Evaluasi dilakukan terhadap hasil pengenalan objek atau pola agar mengetahui tingkat akurasi dari pengenalan tersebut. Perhitungan ini representasikan ke dalam tabel yang disebut sebagai confusion matrix [30]. Representasi confusion matrix diperlihatkan berupa tabel 2.16 berikut ini:

Tabel 2.1 Confusion matrix [30]

\begin{tabular}{|c|c|c|c|}
\hline CLASSI & CATION & \multicolumn{2}{|c|}{ RECOGNITION CLASS } \\
\hline \multirow{3}{*}{$\begin{array}{l}\text { OBSERVED } \\
\text { CLASS }\end{array}$} & \multirow[b]{2}{*}{ Class $=$ YES } & Class $=$ YES & Class $=\mathrm{NO}$ \\
\hline & & $\begin{array}{l}\text { a } \\
\text { (true positive-TP) }\end{array}$ & $\begin{array}{l}\mathrm{b} \\
\text { (false negative-FN) }\end{array}$ \\
\hline & Class $=$ NO & $\begin{array}{l}\text { C } \\
\text { (false positive-FP) }\end{array}$ & $\begin{array}{l}\mathrm{d} \\
\text { (true negative-TN) }\end{array}$ \\
\hline
\end{tabular}

Berdasarkan tabel 2.1, untuk yang dikenali dan benar (true positive) ialah jumlah yang positif benar dalam dataset yang diklasifikasikan positif, True negatives atau yang dikenali tapi tidak benar adalah jumlah yang dikenali tetapi negatif dalam dataset. Sedangkan false positives adalah jumlah yang tidak dikenali tetapi positif berada dalam dataset. Selanjutnya false negatives adalah jumlah yang tidak dikenali dan negatif atau tidak berada dalam dataset. Setelah dilakukan penentuan confusion matrix kemudian akan dilanjutkan dengan perhitungan akurasi dengan persamaan:

$$
\begin{gathered}
\text { Accuracy }=\frac{a+d}{a+b+c+d}=\frac{T P+T N}{F N+F P+T N+T P} \times 100 \\
\text { Recall }=\frac{\text { JumlahTruePositive }}{\text { JumlahTruePositive+JumlahFalseNegative }} \times 100
\end{gathered}
$$




\subsection{Kerangka Pemikiran}

\section{Problem}

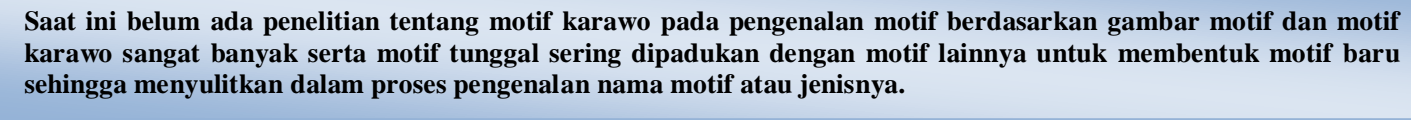

sehingga menyulitkan dalam proses pengenalan nama motif atau jenisnya.

\section{Approach}

Metode yang diterapkan dalam penelitian ini adalah metode ekstraksi fitur Scale Invarian Feature Transform SIFT dan pencocokan fitur Approximate Nearest Neigbor (A-NN), KD-tree, Best Bin First.

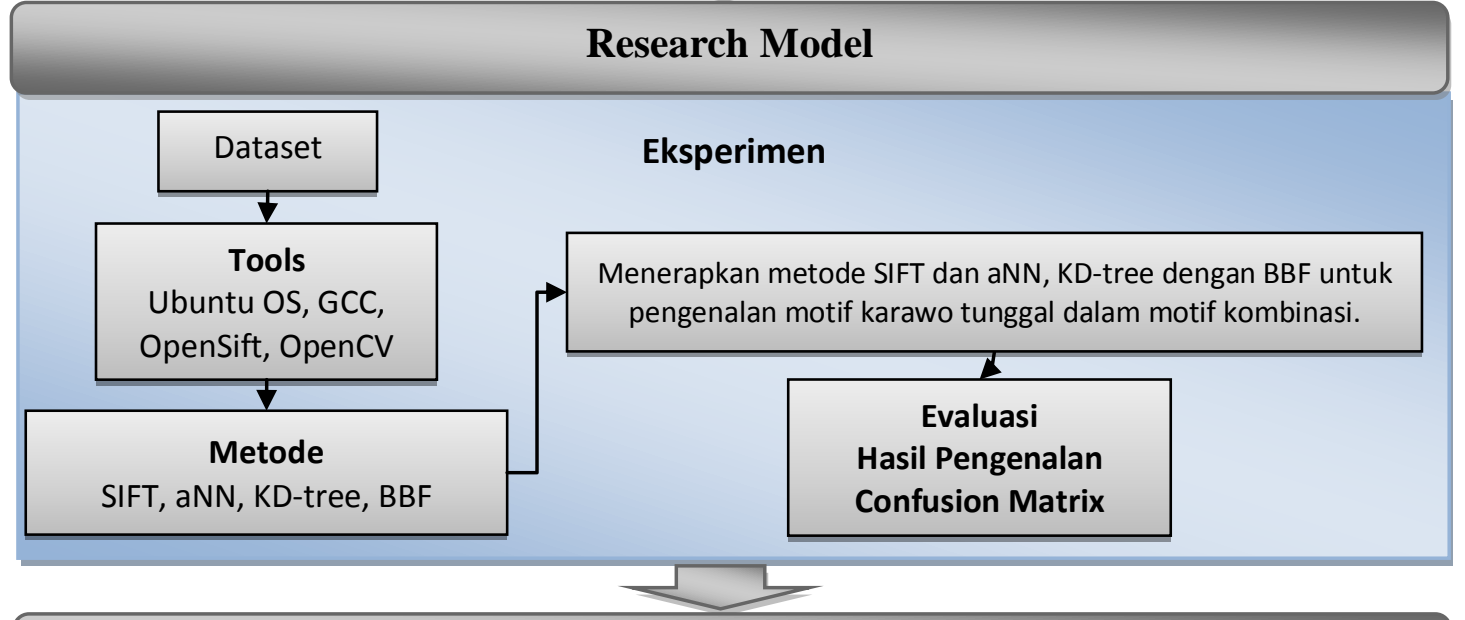

\section{Result}

Hasil Akurasi Pengenalan Citra Motif Karawo pada Penelitian terkait dengan menggunakan ekstraksi fitur SIFT dan Approximate Nearest Neighbor

Gambar 2.1 Kerangka Pemikiran

\section{METODE PENELITIAN}

\section{a) Variabel dan Data Penelitian}

Peneliti menggunakan dataset citra motif Karawo yang diambil dari koleksi "Rumah Karawo" menggunakan kamera DSLR Canon EOS 5D Mark II, penggunaan F-stop f/4 dengan exposure $1 / 30 \mathrm{sec}$, menggunakan ISO-400 dengan focal length $40 \mathrm{~mm}$, serta pencahayaan dari cahaya sekitar tanpa penggunaan flashlight. Dataset dikelompokkan dalam 2 jenis data yaitu data training dan data testing. Tiap jenis data tersebut dibagi dalam 4 jenis motif yaitu: jenis motif alam, motif fauna, motif flora, dan motif geometris. Pada data training motif terdiri dari 30 citra motif alam, motif fauna 24 citra motif, motif flora 24 citra motif, dan motif geometris terdiri dari 75 citra. Data training ini dilakukan proses cropping secara manual dengan software pengolah citra untuk mengambil motif tunggal berukuran lebar 300 dan tinggi menyesuaikan. Pada data testing motif alam terdiri dari 9 citra motif, motif fauna terdapat 4 citra, motif flora 8 citra, dan motif geometris terdiri dari 34 citra motif dengan ukuran sama data training. Waktu pengambilan citra baik data training maupun data testing tidak dikondisikan dalam pencahayaan dan rotasi tidak diperhitungkan mengingat algoritma yang dipakai tidak terpengaruh baik pada skala dan rotasi serta pada pencahayaan. 


\section{b) Perancangan Penelitian}

Metode penelitian yang digunakan dalam penelitian ini merupakan penelitian berbentuk eksperimen dengan tahapan sebagai berikut:

\section{Pengumpulan data}

Penelitian ini diawali dengan pengumpulan data, berupa dataset primer yang diambil dari etalase koleksi "Rumah Karawo" kemudian dikelompokkan dalam 4 jenis yaitu: jenis motif alam, motif fauna, motif flora, dan motif geometris. Dataset dibagi dalam 2 kelompok berupa data training dan data testing selanjuntnya tiap kelompok data akan berisi citra motif sesuai jenisnya. Khusus data training citra motif dilakukan proses cropping secara manual dengan software pengolah citra guna mengambil motif tunggal.

2. Model / metode yang diusulkan

Metode yang diusulkan berupa ekstraksi fitur scale invariant feature transform-SIFT dan metode approximate nearest neighbor (aNN) dengan strategi $\mathrm{BBF}$ untuk menghitung tingkat kesamaan antara data training dan data testing.

3. Eksperimen dan pengujian model

Dataset yang akan diolah dengan software Matlab berupa data training diolah dengan ekstraksi fitur SIFT dan disimpan dalam database, selanjutnya data testing diolah satu persatu dengan ekstraksi fitur SIFT dan fiturnya dibandingkan dengan fitur dalam database dengan approximate nearest neighbor serta dihitung tingkat kesamaannya.

4. Evaluasi dan validasi hasil

Setelah melakukan pengujian terhadap dataset testing berdasarkan hasil perbandingan dari setiap data testing dengan data training maka dapat dihitung tingkat kesamaan secara keseluruhan untuk mendefinisikan tingkat akurasi dari algoritma yang digunakan. Berdasarkan perhitungan jumlah TP, TN, FP, FN kemudian di analisa dan di evaluasi menggunakan confusion matrix, selanjutnya dapat ditarik kesimpulan dari hasil penelitian ini.

\section{c) Metode yang Diusulkan}

Proses pengenalan pada metode usulan dalam penelitian ini melalui 2 tahap yaitu: tahap training dan tahap testing seperti pada gambar 3.1.

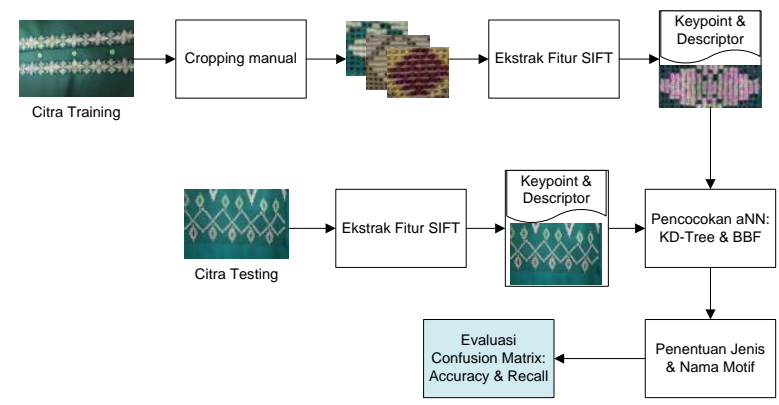

Gambar 3.1 Metode yang diusulkan

Input fungsi tersebut berupa citra RGB. Ekstraksi fitur ini diterapkan baik pada data training maupun data testing langkah-langkah ekstraksi ditunjukkan dalam gambar 3.2. 


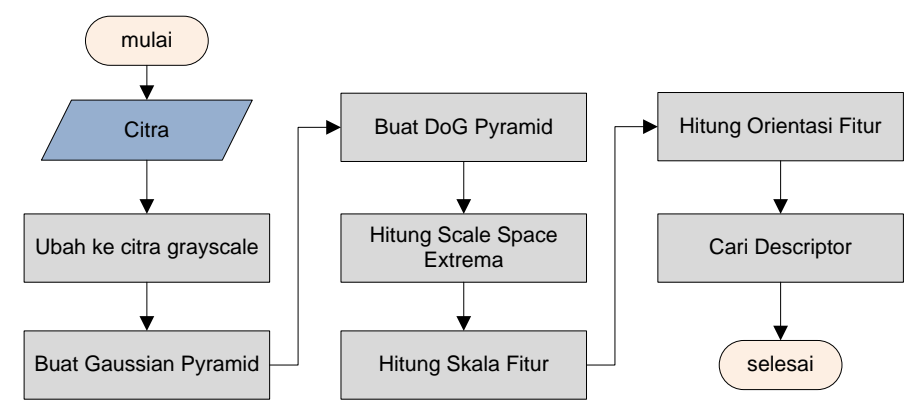

Gambar 3.2 Alur Proses Ekstraksi Fitur SIFT

Penentuan nama dan jenis dilakukan berdasarkan pada hasil pencocokan fitur dengan KD-tree sebelumnya pada semua fitur dari data training. Pada keypoint yang berdekatan $\mathrm{m} \geq 5$ atau jumlahnya yang paling banyak saja sebagai indikasi kesamaan. Nama motif ditentukan sesuai nama dari data training yang yang dibandingkan dengan data testing setelah menghitung kedekatan berdasarkan proses sebelumnya. Nama jenis disesuaikan dengan kelompok dari nama motifnya selengkapnya diperlihatkan pada gambar 3.2.

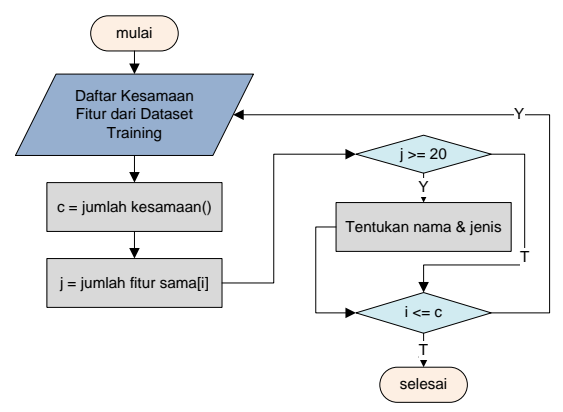

Gambar 3.3 Metode Penentuan Nama dan Jenis Motif

\section{d) Evaluasi dan Validasi Hasil}

Evaluasi terhadap hasil yang terbentuk akan dilakukan dengan pengukuran akurasi. Pengukuran dilakukan dengan menggunakan confusion matrix. Metode ini memperlihatkan perbandingan hasil akurasi dari jumlah TP, jumlah TN, jumlah FP, dan jumlah FN. Berdasarkan perbandingan tersebut selanjutnya dapat diambil kesimpulan tingkat akurasi dan nilai recall dari metode yang digunakan dalam pengenalan citra motif Karawo.

\section{HASIL PENELITIAN}

\section{a) Proses Cropping}

Cropping dilakukan untuk mengekstrak motif tunggal dari citra dan mengumpulkannya dalam jenis yang sama. Penamaan motif hanya mengikuti nama jenisnya diikuti dengan nomor urutnya seperti alam-1-a.jpg berarti motif tersebut masuk dalam jenis alam dengan urutan 1 pada sub urut a.

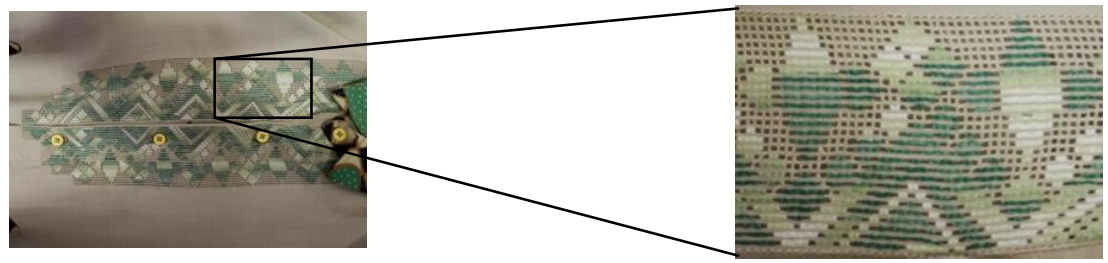

Gambar 4.1 Proses Cropping Motif Tunggal 


\section{b) Ekstraksi Fitur SIFT}

Ekstraksi dilakukan pada citra input menggunakan fungsi dari OpenSift [31] dan OpenCV [32]. Format fitur SIFT mengikuti format oleh D.Lowe [9] yaitu keypoint, skala, orientasi, dan descriptor.
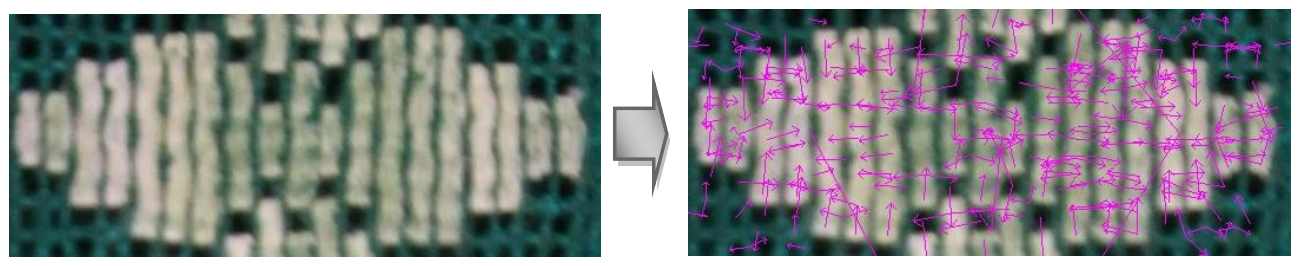

Gambar 4.2 Contoh Motif yang Diekstraksi Fiturnya

\section{c) Pencocokan Fitur SIFT}

Hasil pencocokan dilakukan analisis pada akurasi per jenis untuk melihat hubungannya dengan pengenalan nama motifnya. dilakukan analisis pada recall perjenis untuk melihat hubungannya dengan pengenalan nama motifnya.

Tabel 4.14 Daftar Hasil Pengenalan Nama Motif Per Jenis, m=5

\begin{tabular}{llllllll}
\hline Jenis & TP & TN & FP & FN & Tes & Recall & Accuracy \\
\hline Motif Alam & 5 & 2 & 2 & 0 & 9 & $100 \%$ & $77.78 \%$ \\
Motif Fauna & 4 & 0 & 0 & 0 & 4 & $100 \%$ & $100.00 \%$ \\
Motif Flora & 4 & 0 & 4 & 0 & 8 & $100 \%$ & $50.00 \%$ \\
Motif Geometris & 16 & 11 & 7 & 0 & 34 & $100 \%$ & $79.41 \%$ \\
Total & 29 & 13 & 13 & 0 & 55 & & \\
\hline
\end{tabular}

Pada tabel 4.14 diatas terlihat semua hasil pengenalan nama motif perjenisnya menghasilkan recall $100 \%$ karena dari data tes yang dimasukkan semuanya merupakan data motif karawo yang diambil data yang sama dengan data training (in-sampling). Sedangkan pada akurasinya tertinggi didapatkan pada pengenalan motif fauna sebesar $100 \%$ dan akurasi terendah pada motif flora sebesar $50 \%$.

Tabel 4.15 Daftar Hasil Pengenalan Nama Motif Per Jenis, m=10

\begin{tabular}{llllllll}
\hline Jenis & TP & TN & FP & FN & Tes & Recall & Accuracy \\
\hline Motif Alam & 5 & 4 & 0 & 0 & 9 & $100 \%$ & $100.00 \%$ \\
Motif Fauna & 4 & 0 & 0 & 0 & 4 & $100 \%$ & $100.00 \%$ \\
Motif Flora & 3 & 3 & 2 & 0 & 8 & $100 \%$ & $75.00 \%$ \\
Motif Geometris & 12 & 9 & 13 & 0 & 34 & $100 \%$ & $61.76 \%$ \\
Total & 24 & 16 & 15 & 0 & 55 & & \\
\hline
\end{tabular}

Dari diatas menunjukkan akurasinya tertinggi didapatkan pada pengenalan motif alam dan motif fauna masing-masing sebesar $100 \%$ dan akurasi terendah pada motif geometris sebesar $61,76 \%$.

Tabel 4.16 Daftar Hasil Pengenalan Nama Motif Per Jenis, m=15

\begin{tabular}{llllllll}
\hline Jenis & TP & TN & FP & FN & Tes & Recall & Accuracy \\
\hline Motif Alam & 4 & 2 & 3 & 0 & 9 & $100 \%$ & $66.67 \%$ \\
Motif Fauna & 4 & 0 & 0 & 0 & 4 & $100 \%$ & $100.00 \%$ \\
Motif Flora & 2 & 1 & 5 & 0 & 8 & $100 \%$ & $37.50 \%$ \\
Motif Geometris & 7 & 9 & 18 & 0 & 34 & $100 \%$ & $47.06 \%$ \\
Total & 17 & 12 & 26 & 0 & 55 & & \\
\hline
\end{tabular}


Akurasinya tertinggi didapatkan pada pengenalan motif fauna sebesar $100 \%$ dan akurasi terendah pada motif flora sebesar $37,50 \%$ seperti pada tabel 4.16 .

Tabel 4.17 Daftar Hasil Pengenalan Nama Motif Per Jenis, m=20

\begin{tabular}{llllllll}
\hline Jenis & TP & TN & FP & FN & Tes & Recall & Accuracy \\
\hline Motif Alam & 4 & 1 & 4 & 0 & 9 & $100 \%$ & $55.56 \%$ \\
Motif Fauna & 4 & 0 & 0 & 0 & 4 & $100 \%$ & $100.00 \%$ \\
Motif Flora & 2 & 1 & 5 & 0 & 8 & $100 \%$ & $37.50 \%$ \\
Motif Geometris & 8 & 6 & 20 & 0 & 34 & $100 \%$ & $41.18 \%$ \\
Total & 18 & 8 & 29 & 0 & 55 & & \\
\hline
\end{tabular}

Berdasarkan tabel 4.17 menunjukkan akurasinya tertinggi didapatkan pada pengenalan motif fauna sebesar $100 \%$ dan akurasi terendah pada motif flora sebesar 37,50\%.

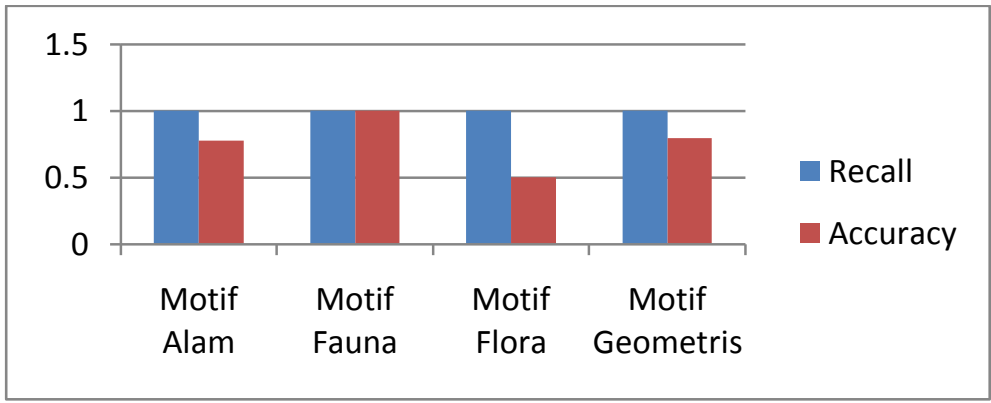

Gambar 4.17 Akurasi dan Recall Nama Motif Berdasarkan Nilai m=5

Dari pembandingan pada gambar 4.17 dapat dilihat recall konsisten pada $100 \%$ karena data tes merupakan sumber dari data training. Akurasi tertinggi pada motif fauna dan terendah pada motif flora.

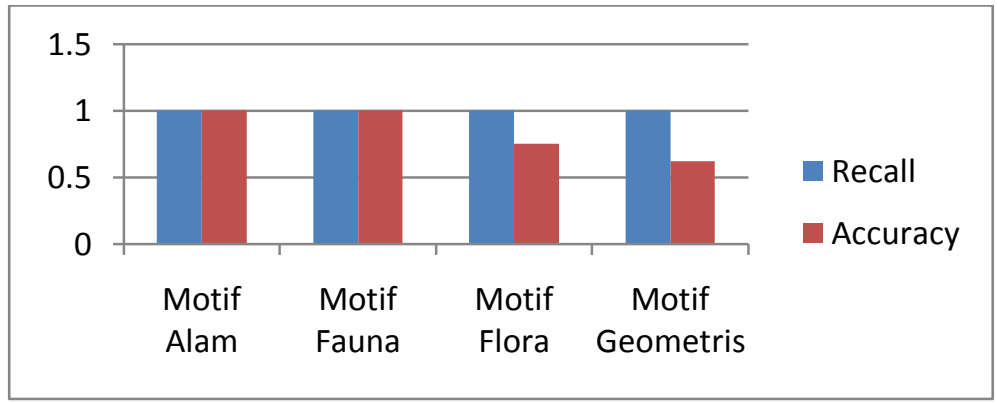

Gambar 4.18 Akurasi dan Recall Nama Motif Berdasarkan Nilai m=10

Nilai pengenalan pada jenis motif geometris turun drastis ini disebabkan karena motif geometris fiturnya dikenali banyak di bawah 10 .

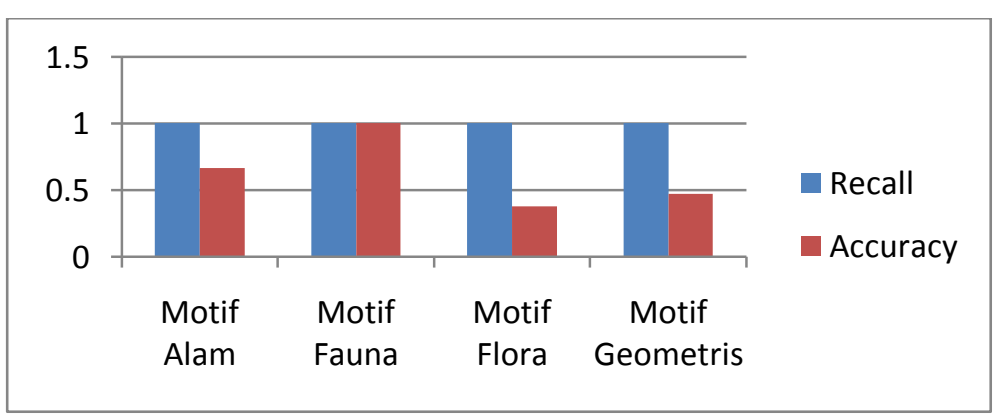

Gambar 4.19 Akurasi dan Recall Nama Motif Berdasarkan Nilai m=15 
Berdasarkan gambar diatas terlihat motif alam dan motif flora sudah mulai turun drastis nilai akurasinya karena motif tersebut fiturnya dikenali sebagian besar dibawah 15 .

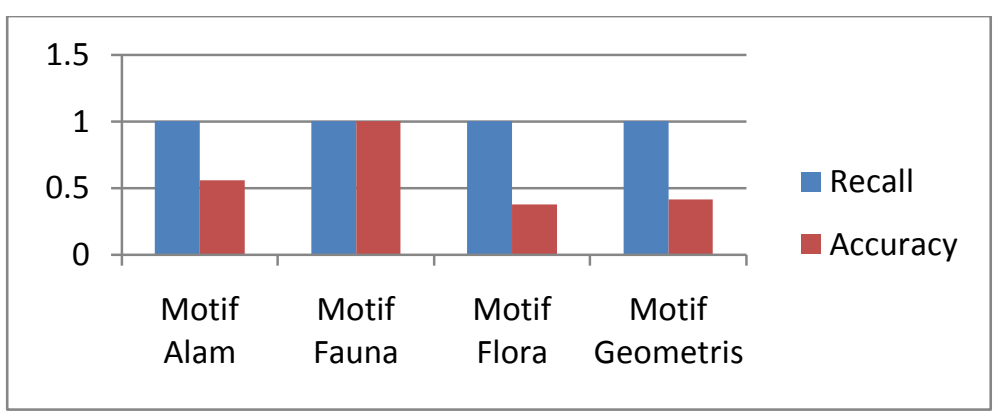

Gambar 4.20 Akurasi dan Recall Nama Motif Berdasarkan Nilai m=20

Pada nilai $m=20$ nilai motif fauna tetap sama karena fitur yg dikenali berada diatas 20 .

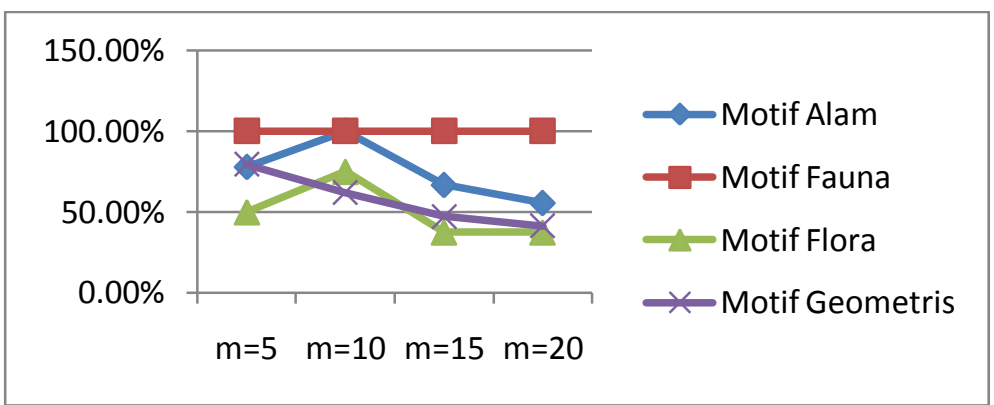

Gambar 4.21 Perbandingan Tingkat Akurasi Nama Motif Berdasarkan Nilai $m$

Perbandingan diatas memperlihatkan akurasi menurun seiring dengan meningkatnya nilai $m$ yang diterapkan. Hal tersebut disebabkan karena nilai fitur yang dikenali pada data testing sebagian besar nilainya berada bawah 10 . Sesuai dengan yang dikemukakan oleh D. Lowe, bahwa untuk mengenali objek minimal 3 [26].

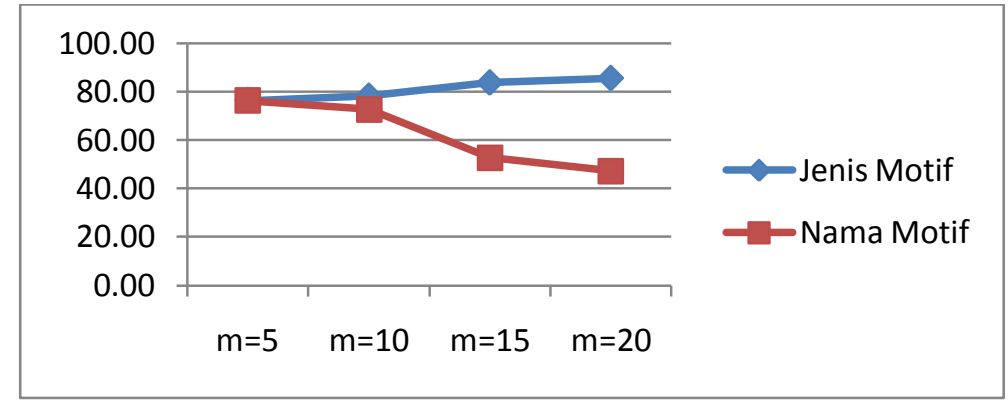

Gambar 4.22 Perbandingan Tingkat Akurasi Nama Motif dan Jenis Motif Berdasarkan Nilai $m$

Perbandingan diatas menunjukkan bahwa pada pengenalan nama motif menurun seiring dengan meningkatnya nilai $m$ akan tetapi akurasi meningkat pada pengenalan jenisnya. Hal tersebut terjadi karena pengenalan nama motif, banyak fitur yang dikenali berada pada motif lain. Fitur-fitur tersebut umumnya adalah lubang sulaman yang berada disekeliling motif.

\section{KESIMPULAN DAN SARAN}

Dari hasil pengujian Approximate Nearest Neighbor dengan penggunaan Best Bin First dan K-NN pada fitur Scale Invariant Feature Transform dalam pengenalan motif Karawo tunggal dalam motif kombinasi memiliki tingkat akurasi sebesar $76,36 \%$ dengan recall $100 \%$ pada pengenalan jenis dan $76,36 \%$ dengan recal $100 \%$ pada nama motif . Konfigurasi yang digunakan pada pengenalan berupa jumlah kesamaan fitur $\geq 5$ sebagai penentu kesamaan. Tingkat akurasi pengenalan yang rendah pada pengenalan nama terpengaruh pada cropping tidak menghilangkan lubang sulaman sehingga hasil 
ekstraksi fitur sift yang cenderung lubang sulaman dijadikan keypoint dari fiturnya sehingga fitur tidak terlalu mencirikan motif itu sendiri.

Dalam penelitian ini menggunakan motif Karawo yang diambil sendiri dari etalase sumber tanpa melalui preprocessing citra yang berarti (hanya cropping manual). Hal ini dapat berpengaruh pada deteksi fitur yang dilakukan oleh SIFT terutama karakteristik Karawo banyak lubang hitam hasil sulaman yang berpotensi besar menjadi keypoint sehingga disarankan untuk menghilangkan lubang tersebut dari citra motif training. Dataset training sebanyak 153 yang dikelompokkan dalam 4 jenis motif Karawo yang pembagiannya tidak seimbang (imbalance) dan terhitung sedikit dibandingkan jumlah motif Karawo sebenarnya berdasarkan jenis motifnya. Saran untuk penelitian selanjutnya agar meningkatkan jumlah dataset training dan dibuat seimbang sehingga akurasi yang dihasilkan dapat lebih relevan. Disarankan untuk mendapatkan hasil akurasi yang lebih baik dengan menerapkan ekstraksi fitur lain khusus bentuk geometrisnya atau melakukan modifikasi pada proses pengenalan baik pada preprocessing (segmentasi latar atau normalisasi grayscale) dan atau pada post processing (filtering keypoint, atau penggunaan pencocokan fitur yang lain).

Kekurangan lain dari penelitian ini adalah belum bisa melakukan pendeteksian objek motif yang sama lebih dari satu pada citra tes dan belum melakukan pengujian pada dataset yang terdapat occlusion atau penghalang. Hasil penelitian ini juga belum praktis karena hanya menerapkan ekstraksi fitur SIFT dan ANN (BBF dan K-NN) pada sistem operasi Linux dengan bahasa C yang antarmuka berupa CLI (Command Line Interface). Saran dari peneliti agar menerapkan algoritma tersebut dengan antarmuka GUI (Graphical User Interface) dan dibuat user friendly sehingga mudah dan dapat digunakan secara praktis dilapangan khususnya dibidang industri motif Karawo.

\section{PENUTUP}

Terima kasih kepada Bapak Purwanto, Ph.D selaku pembimbing utama dan Dr. Moch. Arief Soeleman, M.Kom selaku pembimbing pembantu yang sangat membantu dalam penyusunan tesis ini.

"Saya menyatakan dan bertanggung jawab dengan sebenarnya bahwa Artikel ini adalah hasil karya saya sendiri kecuali cuplikan dan ringkasan yang masing-masing telah saya jelaskan sumbernya"

Syahrial - P31.2014.01688

\section{DAFTAR PUSTAKA}

[1] Rahmatiah, "Industrialisasi Kerajinan Sulaman Karawo dan Perubahan Sosial Budaya Gorontalo," Disertasi Doktor, Tidak dipublikasikan. Universitas Negeri Gorontalo, Gorontalo, 2014.

[2] Hasdiana., F. . Adiatmono, and U. Naini, "Peningkatan Brand Image Kerawang Melalui Penciptaan Desain Ragam Hias Kreatif Beridentitas Kultural Budaya Gorontalo Untuk Mendukung Industri Kreatif,” Laporan Penelitian Strategis Nasional, Tidak dipublikasikan, Gorontalo, 2013.

[3] A. Mulyanto, M. Rohandi, and M. S. Tuloli, "Klasifikasi Karakter Pengguna Karawo Untuk Rekomendasi Motif Menggunakan Algoritma Naïve Bayes," Laporan Penelitian Hibah Bersaing, Tidak dipublikasikan, Gorontalo, 2013.

[4] M. H. Koniyo, S. A. Lamusu, L. Hadjaratie, and A. A. Bouty, "Perancangan Aplikasi Rekomendasi Motif Karawo Berdasarkan Karakter Pengguna Berbasis Budaya Gorontalo," SEMNASTEK, ISSN:2407-1846, no. November, p. 8, 2015.

[5] B. Arisandi, N. Suciati, and A. Y. Wijaya, "Pengenalan Motif Batik Menggunakan Rotated Wavelet Filter Dan Neural Network," JUTI, vol. 9, no. Juli, pp. 13-19, 2011.

[6] M. A. Suryawan, A. Hakim, Santi, and Nirwana, "Identification of Batik Motive Pattern Based on Object Oriented Using Decision Tree Approach," IPSJ SIG, pp. 1-4, 2013.

[7] J. W. Yodha and A. W. Kurniawan, "Pengenalan Motif Batik Menggunakan Deteksi Tepi Canny Dan K-Nearest Neighbor," Techno.COM, vol. 13, no. 4, November, pp. 251-262, 2014. 
[8] I. Nurhaida, A. Noviyanto, R. Manurung, and A. M. Arymurthy, “Automatic Indonesian's Batik Pattern Recognition Using SIFT Approach,” Procedia Comput. Sci., vol. 59, no. Iccsci, pp. 567-576, 2015.

[9] D. G. Lowe, "Distinctive Image Features from Scale-Invariant Keypoints," Int. J. Comput. Vis., pp. 1-28, 2004.

[10] M. Aly, "Face Recognition using SIFT Features," CNS186 Term Proj., pp. 1-7, 2006.

[11] P. Scovanner and S. Ali, "A 3-Dimensional SIFT Descriptor and its Application to Action Recognition," ACM, pp. 357-360, 2007.

[12] C. Ancuti and P. Bekaert, "More Effective Image Matching with Scale Invariant Feature Transform," ACM, vol. 4, no. 7, pp. 71-78, 2007.

[13] M. Das, J. Farmer, A. Gallagher, and A. Loui, "Event-based Location Matching for Consumer Image Collections," ACM, vol. 7, no. 8, pp. 339-347, 2008.

[14] Y. Ke and R. Sukthankar, "A More Distinctive Representation for Local Image Descriptors," Res. Intel, 2003.

[15] J. Joglekar and S. S. Gedam, "Image Matching With Sift Features - A Probabilistic Approach," IAPRS, vol. XXXVIII, no. September, pp. 7-12, 2010.

[16] J. S. Beis and D. G. Lowe, "Shape indexing using approximate nearest-neighbour search in high-dimensional spaces," in Proceedings of IEEE Computer Society Conference on Computer Vision and Pattern Recognition, 1997, pp. 1000-1006.

[17] J. Kybic and I. Vnucko, "Approximate Best Bin First kd Tree All Nearest Neighbor Search with Incremental Updates," Res. Rep. C., 2010.

[18] M. Brown, R. Szeliski, and S. Winder, "Multi-Image Matching using Multi-Scale Oriented Patches."

[19] A. H. Rangkuti, A. Harjoko, and A. E. Putro, "Content Based Batik Image Retrieval," JCS, vol. 10, no. 6, pp. 925-934, 2014.

[20] A. Kurniawardhani, N. Suciati, and I. Arieshanti, "Klasifikasi citra batik menggunakan metode ekstraksi ciri yang," JUTI, vol. 12, pp. 48-60, 2014.

[21] K. A. Nugraha, W. Hapsari, and N. A. Haryono, "Analisis Tekstur Pada Citra Motif Batik Untuk Klasifikasi Menggunakan k-NN,” INFORMATIKA, vol. 10, no. 2, pp. 135-140, 2014.

[22] I. Setyawan, I. K. Timotius, and M. Kalvin, "Automatic Batik Motifs Classification using Various Combinations of SIFT Features Moments and k -Nearest Neighbor," in 7th International Conference on Information Technology and Electrical Engineering-ICITEE, 2015, no. February, pp. 269-274.

[23] S. Arya, D. M. Mount, N. S. Netanyahu, and A. Y. Wu, "An Optimal Algorithm for Approximate Nearest Neighbor Searching in Fixed Dimensions," in Proceedings of the Fifth Annual ACM-SIAM Symposium on Discrete Algorithms, 1994, vol. 1, no. 212.

[24] P. Bhowmick and B. B. Bhattacharya, "Approximate fingerprint matching using kd-tree Approximate Fingerprint Matching Using Kd-tree," IEEE, 2004.

[25] M. S. Nixon and A. S. Aguado, Feature Extraction \& Image Processing for Computer Vision, 3th ed. Academic Press, 2012.

[26] D. G. Lowe, "Object Recognition from Local Scale-Invariant Features," in International Conference on Computer Vision, Corfu, 1999.

[27] M. Muja and D. G. Lowe, "Scalable Nearest Neighbour Algorithms for High Dimensional Data," IEEE Trans. Pattern Anal. Mach. Intell., vol. 36, no. 11, pp. 2227-2240, 2014.

[28] S. Skiena, The Algorithm Design Manual, 2nd ed. London: Springer-Verlag, 2008.

[29] M. De Berg, O. Cheong, M. Van Kreveld, and M. Overmars, Computational Geometry: Algorithms and Applications, vol. 17. 2008.

[30] I. H. Witten, E. Frank, and M. A. Hall, Data Mining Practical Machine Learning Tools and Techniques, 3th ed. MA, USA: Morgan Kaufmann Publishers, 2013.

[31] R. Hess, “An open-source SIFTLibrary,” ACM, pp. 1493-1496, 2010.

[32] R. Laganière, OpenCV 2 Computer Vision Application Programming Cookbook. Birmingham,UK: Packt Publishing, 2011. 